NBER WORKING PAPER SERIES

\title{
A DECOMPOSITION OF THE ELASTICITY \\ OF MEDICAID NURSING HOME \\ EXPENDITURES INTO PRICE, QUALITY, AND QUANTITY EFFECTS
}

Paul J. Gertler

Working Paper No. 1751

\author{
NATIONAL BUREAU OF ECONOMIC RESEARCH \\ 1050 Massachusetts Avenue \\ Cambridge, MA 02138 \\ October 1985
}

I am indebted to Robin Allen, Thomas Coleman, Roger Feldman, Therese McGuire, Robert Porter, and Warren Sanderson for helpful suggestions. Of course, I am responsible for any remaining errors. The research reported here is part of the NBER's research program in Health Economics and project in Government Budgets. Any op inions expressed are those of the author and not those of the National Bureau of Economic Research. 
NBER Working Paper \#1751 Novenber 1985

A Decomposition of the Elasticity of Medicaid Nursing Home Expenditures into Price, Quality, and Quantity Effects

\section{ABSTRACT}

Nursing home expenditures have become a public policy concern primarily because the Medicaid program payes for approximately 50 percent. Medicaid makes health care available to individuals who otherwise could not afford it, by directly reimbursing nursing homes for Medicaid patient care. Typically, Medicaid reimbursement rates are set by a cost plus method, where the reimbursement per patient is equal to average cost plus some return referred to as the Medicaid "plus" factor. This paper estimates the elasticity of Medicaid expenditures with respect to a change in the Medicaid "plus" factor. and decomposes that elasticity into price, quality, and quantity components. The decomposition is derived from a model of nursing home behavior, which shows that an increase in the Medicaid "plus" factor causes nursing homes to admit more Medicaid patients and reduce quality.

Total expenditures are the Medicaid reimbursement rate times the number of Medicaid patients receiving care. An increase in the Medicaid "plus" factor affects the Medicaid reimbursement by directly raising the Medicaid "plus" factor, and by indirectly decreasing average cost through a reduction in quality. These are the price and quality effects, respectively. The quantity effect is change in the number of Medicaid patients. The elasticities are estimated separately for proprietary and "rot for profit" nursing homes using a 1980 sample of New York nursing homes. Uniformly, the proprietary elasticities are approximately twice as large as the "not for profit" elasticities. As expected the price and quantity effects are positive, and the quality effects are negative. In the decomposition, the quality effect is quite important. In fact, ignoring it would lead to a fifty-three percent overestimate of the Medicaid expenditure elasticity.

Paul J. Gertler Department of Economics State University of New York Stony Brook, New York 11794 


\section{INTRODUCTION}

Nursing home expenditures have become a public polfcy concern primarily because government programs pay for approximately 50 percent of the expenditures. Specificaliy, in 1983, government expenditures accounted for $\$ 14$ bilition out of the $\$ 28.4$ billion spent on nationally Nursing home care. Moreover, approximateiy 30 percent of the public expenditures were financed through the Medicaid program."

The Medicaid program makes heclth care available to individuals who otherwise could not afford it. It is jointly financed by state and Federal goverrmerits, but administered on a state basis. Medicaid reimburses nursing homes a set fee for the care of Medicaid patients. Typically, Medicaid reimbursement rates are set by a cost plus method, where the reimbursement per patient is equal to average cost plus some return referred to as the Medicaid "plus" factor. 2 This paper estimates the elasticity of Medicaid expenditures with respect to a change in the Medicaid "plus" factor, and decomposes that elasticity into price, quality, and quantity components.

The decomposition is derived from a model of nursing home behavior, which is determined to a large extent by government regulation. specifically, the Medicaid program allows nursing homes to price discriminate between patients who finance their care privately and patients whose care is financed by Medicaid. Nevertheless, nursing homes are required to provide the same quality to both types of patients. Finally, the total number of patients (capacity) is 1 imited by the Certificate of Need (CON) cost containment program. ${ }^{3}$

In essence, the Medicaid program creates a second market for nursing home care, and CON restricts supply so that there is excess Medicald demand. 4 Therefore, Medicaid demand is perfectly elastic at the Medicaid reimbursement rate, while "private pay" demand is sensitive to price and quality. Hence, nursing homes compete for "private pay" patients knowing that they can always admit Medicaid patients at the Medicaid reimbursement rate if they have excess capacity. Quality is determined by the "private pay" market. The greater is "private pay" demand relative to Medicaid, the higher is quality.

An increase in the Medicaid "plus" factor causes nursing homes to admit more Medicaid patients, and reduce quality. ${ }^{5}$ The increase in the "plus" factor raises the marginal profit of a Medicald patient. Therefore, homes have incentive to substitute Medicaid patients for "private pay" patients. Homes reduce "private pay" demand and operating costs by lowering quality. 
Using these results we decompose the Medicaid expenditure elasticity into price, quality, and quantity effects. Total expenditures are the Medicaid reimbursement rate times the number of Medicald patients receiving care. An increase in the Medicaid "plus" factor affects the Medicaid reimbursement rate two ways: (i) by directly raising the Medicald "plus" factor, and ( $i$ ) by indirectly decreasing average cost through a reduction in quality. These are the price and quality effects, respectively. The price effect is positive, while the quality effect is negative. Finaily, the quantity effect is positive, as the rise in the "plus" factor causes homes to increase their number of Medicaid patients.

The elasticities are estimated separately for proprietary and "not for profit" nursing homes using a 1980 sample of New York nursing homes. Uniformly, the proprietary elasticities are approximately twice as large as the "not for profit" elasticities. Specifically, the total proprietary Medicaid expenditure elasticity is .117 , and the "not for profit" elasticity is .061 . As expected the price and quantity effects are positive, and the quality effects are negative. Translating these elasticities into dollars shows that a one percent rise in the Medicaid "plus" factor $(\$ .68$ per patient day for proprietary homes, and \$.42 per patient day for "not for profit" homes) leads to approximately $\$ 1,317 \mathrm{million}$ increase in annual Medicaid expenditures.

In the decomposition, the quality effect is quite important. In fact, ignoring it would lead to a substantial overestimate of the Medicaid expenditure elasticity. The quality effect is -.064 for proprietary homes and -.027 for "not for profit" homes. In dollar terms, the quality effect of a one percent rise in the Medicaid "plus" factor amounts to a decrease of approximately $\$ 694 \mathrm{million}$ in Medicaid expenditures. Hence, if the quality effect were ignored, the expenditure elasticity would be overstated by approximately fifty three percent.

The theoretical analysis presented in section II and is based on Gertler (1985a) and (1985b). The model employs the notion that there are quantity and quality aspects to production, and both quantity and quality are endogenous. 6 specifically, nursing homes produce a series of commodities, such as medical care, room and board, and social activities. The quality of nursing home care is the utflity patients derive from consuming this package. Nursing home output, then, is characterized by the total number of patients and average quality. The decomposition of the Medicaid elasticity is derived in section III, and estimated in section IV. Finally, conclusions are drawn in section $V$. 
II. A THEORY OF NURSING HOME BEHAVIOR

\section{A. Assumptions and Notation}

Nursing homes face "private pay" and Medicaid demand. "Private pay" demand is given by $X(P, O)$, where $X$ is the number of "private pay" patients, $P$ is the price charged "private pay" patients, and 0 is average quality. "Private pay" demand is increasing in $Q$,and decreasing in $P$. In contrast, Medicaid demand is perfectly elastic at the Medicaid reimbursement rate.

CON imposes a capacity constraint on each home. Since there is excess Medicaid demand, the constraint is binding. It is specifled as

$$
X+M=X
$$

where $M$ is the number of Medicaid patients and $Z$ is the CON allowed capacity. Nursing homes are required to provide all patients with the same level of quality. Therefore, a nursing home's cost function can be specified as a function of the total number of patients receiving care and average quality. Let the cost function for providing quality level 0 to $Z$ patients be given by $C(0)$. It is assumed to be increasing and convex.

Finally, Medicaid reimburses a nursing home its average cost plus $r$, the Medicaid "plus" factor. Hence, the Medicaid reimbursement per patient is

$$
R=r+c(0) / R \text {. }
$$

\section{B. Proprietary Mursing Home Behavior}

Homes choose "private pay" price and quality so as to maximize profits subject to the con capacity constraint. The profit function is

$$
\Pi=P X(P, 0)+R[X-X(P, 0)]-C(0) .
$$

The first order conditions are

$$
\begin{aligned}
& p x_{p}+x=R x_{p} \\
& P x_{0}=(x / R) c_{0}+R x_{0} .
\end{aligned}
$$

"Private pay" price is chosen in (4) such that marginal "private pay" revenue equals the opportunity cost of Medicaid revenue, and quality is chosen in (5) such that marginal "private pay" revenue equals the marginal cost of quality plus the opportunity cost of Medicaid revenue. Since the cost of caring for 
plus the opportunity cost of Medicaid revenue. Since the cost of caring for Medicaid patients is recovered via Medicaid reimbursement, the marginal cost of quality is weighted by the proportion of "private pay" patients.

An increase in the Medicaid "plus" factor causes nursing homes to increase its number of Medicaid patients and lower quality. ${ }^{7}$ The rationale behind this result is that an increase in $r$ raises marginal Medicaid revenue, making Medicaid patients more profitable. Therefore, (since the con capacity constraint is binding) homes want to substitute Medicaid patients for "private pay" patients. Homes can reduce "private pay" demand by increasng their "private pay" price and by lowering their quality. They surely lower quality, since that also reduces their operating costs.

\section{C. "Not For Profit" Nursing Home Behavior}

Unlike proprietary nursing homes, the objectives of "not for profit" homes are not well defined. Economists typically model "not for profit" firms as utility maximizers. 8 The arguments of a "not for profit" firm's utility function are debatable ard depend upon the institutional setting. In the nursing nome industry, where the religious institution dominates, we assume that not for profit homes are basically altruistic in nature. Therefore, we expect these homes to be concerned with quality, and with providing care to the poor. Hence, the "not for profit" nursing home's utllity function is assumed to be an increasing function of quality and the number of Medicaid patients. "Not for profit" nursing homes are assumed to choose "private pay" price and quality so as to maximize utility subject to the con capacity corstraint and subject to a break even constraint. ${ }^{9}$

Let $G(O, M)$ be the nursing home's utility function, and $\lambda$ the Lagrange multiplier on the break even constraint. Then, assuming that the kuhn-Tucker conditions are are satisfied at an interior solution, the first order conditions are

$$
\begin{aligned}
& P x_{P}+x-(1 / \lambda) G_{M} x_{P}=R x_{P} \\
& P x_{0}+(1 / \lambda)\left(G_{0}-G_{M} x_{0}\right)=(x / \lambda) C_{0}+R x_{0} .
\end{aligned}
$$

"Private pay" price is chosen in (6) such that marginal "private pay" revenue plus the marginal utflity of Medicaid patients equals the opportunity cost of Medicaid revenue, and quality is chosen in (7) such that the marginal "private pay" revenue pius the marginai utiiity of quaitity equais the marginal cost of quality and marginal opportunity cost of Medicaid revenue. 
An adjustment in the Medicaid "plus" factor affects the "not for profit" nursing home's first order conditions in exactly the same way as it affects the proprietary first order conditions. Therefore, the directions of "not for profit" nursing homes responses to policy changes are the same as proprietary nursing homes responses, but magnitudes of response may differ.10

\section{A DECOMPOSITION OF THE MEDICAID EXPENDITURE ELASTICITY}

Total Medicaid nursing home expenditures, denoted $E$, are defined as the Medicaid reimbursement rate times the number of Medicaio patients receiving care :

$$
E=R M \text {. }
$$

Differentiation of (8) with respect to the Medicaid "plus factor yields

$$
\frac{\partial E}{\partial r}=M+\left(\frac{\partial C}{\partial 0} \frac{\partial 0}{\partial r}\right) \frac{M}{\bar{R}}+\frac{\partial M}{\partial r} R .
$$

In (9) the change $E$ with respect to a change in $r$ is decomposed into three effects: (i) a price effect, (1i) a quality effect, and a (iji) quantity effect. The first term in (9) is the price effect, which is just the direct effect of a change in $r$ on $R$. That magnitude is one times the number of Medicaid patients. The second term is the quality effect, which is the indirect effect on $R$ via a change in average cost. Specifically, an increase in $r$ is incentive for homes to reduce quality. If the cost function is convex in quality, then average cost falls. The magnitude of the indirect effect is the change in average cost times the number of Medicaid patients. The third term is the quantity effect. An increase in $r$ is incentive for homes to increase their number of Medicald patients. The magnitude of the quantity effect is the change in the number of Medicaid patients times the Medicaid reimbursement rate. 
6

The decomposition in (9) can be expressed in elasticity form as:

$$
n_{E}=\frac{r}{R}+n_{C} \frac{C / R}{R}+n_{M} \text {. }
$$

where $n_{E}$ is the elasticity of Medicaid expenditures with respect to a change in $r$, $\eta_{C}$ is the elasticity of total cost with respect to a change in $r$, and $n_{M}$ is the elasticity of the number of Medicaid patients with respect to a change in r. 11 The Medicald expenditure elasticity in (10) is decomposed into three terms: (i) the ratio of the Medicaid "plus" factor to the reimbursement rate, which is the price effect, (ii) the cost elasticity weighted by the ratio of average cost to the Medicaid reimbursement rate which is the quality effect, and ( $1 i j$ ) the Medicaid patient elasticity which is the qunatity effect.

\section{CALCULATION OF THE MEDICAID EXPENDITURE ELASTICITY}

\section{A. Methods}

The difficult part in calculating (10) is the estimation of $n_{c}$ and $n_{m}$. We begin by specifying a linear specification of the solution to the first order conditions referred to as the reduced form. ${ }^{12}$ The Medicaid patients and quality reduced form equations for ith nursing home are

$$
\begin{aligned}
& M_{i}=\beta_{10}+\sum_{j=1}^{J} \beta_{1 j} Z_{i j}+\sum_{k=1}^{k} \beta_{1, j+k} W_{i k}+\varepsilon_{1 i} \\
& 0_{i}=\beta_{20}+\sum_{j=1}^{J} \beta_{2 j} Z_{i j}+\sum_{k=1}^{k} \beta_{2, j+k} W_{i k}+\varepsilon_{2 i},
\end{aligned}
$$

where the $Z_{i j}$ 's include exogenous demand variables, the Medicaid "plus" factor, and the market concentration level implied by CON policy. The $W_{i j}$ 's are exogenous supply variables: input prices, capital stock, and the CON capacity constraint. Finally, the $\beta_{i j}$ 's are unknown parameters, and the $\varepsilon_{i j}$ 's are independently distributed random variables with zero mean.

Estimation of (11) allows us to calculate $n_{M}$ by multiplying the coefficient on $r$ in (11) times the ratio of $r$ to $M$. On the other hand, because quality is not easily odserved and problems of simultinaity, calculation of $n_{C}$ is more difficult. To avoid these problems we estimate a reduced form cost 
function. We begin with a first order linear approximation of the structural cost function 13

$$
c_{i}=\alpha_{0}+\sum_{k=1}^{k} \alpha_{k} w_{i k}+\varepsilon_{3 i}
$$

Substitution of (12) into (13) yields the reduced form cost function

$$
c_{i}=\gamma_{0}+\sum_{j=1}^{J} \gamma_{j} z_{i j}+\sum_{k=1}^{K} \gamma_{J+k} w_{i k}+E_{4 i},
$$

which allows us to calculate $n_{C}$ by mulitplying the estimated coefficient on $r$ in (14) times the ratio of $r$ to $C$.

\section{b. Data}

The data are constructed from New York state's 1980 survey of Long Term Care facilities. The sample consists of 455 nursing homes chosen from 798 possible cases. Excluded were government homes, hospital attached homes, and non-reporting homes. In the sample are 288 proprietary and 167 "not for profit" nursing homes. Unless otherwise specified, the variables are daily averages, with the unit of observation being the nursing home. Descriptive statistics are presented in table 1.

The dependent variables are the number of Medicaid patients, and total variable costs. The exogenous supply variables are the input prices and capttal stock. The input prices are the hourly nursing wage rate, the hourly other labor wage rate, and a supplies price index. ${ }^{14}$ since, the majority of capital owned by a nursing home is the facility itself, capital stock is measured as total area of the facility in 100,000's of square feet. The exogenous demand variables are the per captta income of the people living in the nursing home's market area, the population over age 65 in the nursing home's market area, the proportion of "private pay" patients in the nursing home whose last residence before entering the nursing home was located in the same county in which the nursing home is located, and an index of heaith status of the patients in the nursing home. Income is measured in 1000 's of dollars, and population in 10,000's of people. The income and population data come from the 1980 census. The proportion of "private pay" patients from the same county is a measure of the distance of the nursing home from the family and friends of its patients. Presumably, nursing homes that are located closer to its patients' family and friends are more attractive, ceteris paribus. The health index is really an index of 111 -health.15 
DESCRIPTIVE STATISTICS: $\frac{\text { TABLE }^{1}}{\text { MEANS }}$ AND STANDARD DEVIATIONS VARIABLE ALL HOMES PROPRIETARY NOT FOR PROFIT

\begin{abstract}
1. Total cost
\end{abstract}
2. Medicaid Patients

3. Medicaid Reimbursement Rate

4. Average cost

\section{Medicaid Plus} Factor

6. Nursing Hourly Wage

7. Other labor Hourly Wage

8. Supplies Price

9. Capital Stock

10. Per Capita Income
11. Population Over 65
12. Z Patients Same County
13. Health Status Index

\section{Total}

Patients
15. Market Concentration

16. *f Observations

\author{
5913.62 \\ (6118.81)
}

$$
100.51
$$

( 90.67$)$

$$
\begin{gathered}
49.95 \\
(13.52)
\end{gathered}
$$

44.09

(13.61)

$$
\begin{gathered}
5.80 \\
(5.01)
\end{gathered}
$$

$$
7.82
$$

(2.75)

\subsection{7}

(2.78)

1.41
$(.10)$

$$
6.86
$$

$(25.51)$

$$
7.15
$$

(1.40)

$$
1.07
$$

$(.88)$

$$
\begin{aligned}
& .74 \\
& (.26)
\end{aligned}
$$

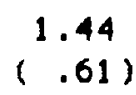

$$
124.47
$$

(94.04)

$\left(\begin{array}{l}.12 \\ (.11)\end{array}\right.$

455
5489.72

(4955.44)

99.17

(85.88)

$\begin{array}{cc}48.37 & 52.66 \\ (11.56) & (16.04)\end{array}$

$$
41.51
$$

(11.18)

48.54

(16.09)

$$
\begin{gathered}
6.86 \\
(3.91)
\end{gathered}
$$

4.12

(6.11)

$$
7.67
$$

(2.84)

8.06

(2.59)

$$
7.97
$$

(2.44)

$$
8.79
$$$$
\text { (3.23) }
$$

$$
\begin{gathered}
1.38 \\
(.03)
\end{gathered}
$$

1.44

(.15)

$\begin{array}{cc}7.04 & 6.54 \\ (31.77) & (5.84)\end{array}$

7.27

(1.32)

$$
\begin{gathered}
7.08 \\
(1.44)
\end{gathered}
$$

$$
1.23
$$$$
(.87)
$$

.98
$(.87)$

$$
\begin{aligned}
& .70 \\
& (.30)
\end{aligned}
$$

$(.24)$

$$
1.51
$$

1.31

(.67)

$(.57)$

124.61

( 89.33$)$

124.21

(101.94)

$\begin{array}{ll}.12 & .11 \\ .12 & (.09)\end{array}$

288 
Since nursing homes compete only for "private pay" patients the appropriate market to analyze is the "private pay" patient market. Each home's geographic "private pay" patient market is somewhat complicated to measure since the data is reported on a county basis. The problem is that a nursing home's market may not be completely commensurate with the county in which it is located. In particular, homes that are located on county borders certainly compete for "private pay" patients from both counties. Instead, separate market areas are defined for each nursing home based on "private pay" patient census data. For each nome, the survey reports the number of "private pay" patfents from each county in New York stite currently residing in the home. Homes participate in several county private pay patient markets. A home's participation in a county market is given by the proportion of the home's "private pay" patients from that county. Thus, a home's market area is defined as the counties in which its "private pay" patients last resided, and the proportion of its "private pay" patients from each county. This market definition guides the computation of the market variables.10

The policy variables are the Medicaid plus factor, the con capacity constraint, and the conceritration of the home's "private pay" patient market area. New York computes the plus factors based on owner's equity in the facility. Therefore, there is cross-sectional variation in the Medicaid plus factor. The CON capacity constraint is measured as the average dally census of patients in the home, and CON entry policy is captured by a Herfindahl index of the concentration of each home's "private pay" market. 17 Entry reduces the concentration of a home's "private pay" patient market.

\section{Results}

Since the reduced form equations (10) and (14) have the same right hand side variables with no cross equation restrictions, they can be effciently estimated by least squares. Separate reduced forms were estimated for proprietary and "not for profit" homes as hypothesis tests overwelmingly reject pooling. The estimates are presented in tables 2 and 3 , respectively.

The results of the estimation are quite reasonable as the estimated equations exribit substantial precision and high R-squares. In addition, the reduced form cost functions are increasing in quantity and input prices, and the coefficient on the Medicaid "plus" factor is, as expected, negative and significantly different from zero. Further, the Medicald "plus" factor is positive in the reduced form Medicaid patients equations, and significantly different from zero in the proprietary case. 
TABLE 2

PROPRIETARY REDUCED FORM

ESTIMATED COEFFICIENTS AND T-STATISTICS IN PARENTHESES

INDEPENDENT

VARIABLE

1. CONSTANT

2. TOTAL \# OF PATIENTS

3. NURSING HOURLY WAGE

4. OTHER LABOR'S HOURLY WAGE

5. SUPPLIES

PRICE

6. CAPITAL STOCK

7. HEALTH STATUS

8. INCOME

9. POPULATION

10. MEDICAID PLUS FACTOR

11. I PATIENTS SAME COUNTY

12. MARKET CONCENTRATION

13. R-SOUARED
TOTAL COST

$-5495.40$

(1.42)

$48.29^{* *}$

(49.12)

$408.00^{* *}$

$(5.02)$

$-11.63$

7.81

$(.03)$

$$
-.05
$$

(. .02)

$1418 \cdot 50^{* *}$

( 9.30$)$

56.35

(.91)

$-542.52 * *$

(3.61)

$-58.80^{* *}$

( 2.98$)$

259.34

( . .80)

941.06

( 1.06$)$

.94
MEDICAID

PATIENTS

$-22.68$

(. .46)

$(72.82)$

$3.57^{* *}$

( 3.44 )

$-.75$

(. .68)

7.07

(.20)

$-.02$

(. .65)

$-3.25^{*}$

(1.66)

$-3.33^{* *}$

(4.21)

3. 32 *

( 1.94 )

$$
\left(\begin{array}{l}
.49^{* *} \\
(1.96)
\end{array}\right.
$$

$-6.95 *$

(1.69)

33. $22^{* *}$

( 2.96$)$

.97

** Coefficient is significantly different from zero at the .05 level

* Coefficient is significantly different from zero at the 10 level 
TABLE 3

"NOT FOR PROFIT" REDUCED FORM

ESTIMATED COEFFICIENTS AND T-STATISTICS IN PARENTHESES

INDEPENDENT

VAR I ABLE

1. CONSTANT

2. TOTAL * OF PATIENTS

3. NURSING HOURLY WAGE

4. OTHER LABOR'S HOURLY WAGE

5. SUPPLIES

PRICE

6. CAPITAL STOCK

7. HEALTH STATUS

8. INCOME

9. POPULATION

10. MEDICAID PLUS FACTOR

11. $\%$ PATIENTS SAME COUNTY

12. MARKET

CONCENTRATION

13. R-SOUARED
TOTAL COST

$-16016.50^{* *}$

( 6.62$)$

$55.45^{* *}$

(13.90)

43.38

$(.30)$

188.66

(1.47)

$5224.88^{* *}$

( 3.52$)$

$124.10^{*}$

(1.82)

$2464.94^{* *}$

(8.98)

62.37

(.44)

$630.59^{* *}$

(1.98)

$-48.01^{*}$

(1.80)

457.74

(.83)

$6091.84^{* *}$

(2.25)

.94
MEDICAID

PATIENTS

$-69.94^{* *}$

( 3.04$)$

$1.01^{* *}$

$(26.83)$

$$
\begin{aligned}
& .83 \\
& (\quad .60)
\end{aligned}
$$

$$
1.02
$$$$
\text { (.84) }
$$

$29.55^{* *}$

(2.06)

$-2.57^{* *}$

( 3.98 )

$8.96^{* *}$ (3.44)

$-1.57$

(1.17)

$$
\begin{aligned}
& 7.09^{* \star} \\
& (2.35) \\
& .25 \\
& (1.00)
\end{aligned}
$$

$-12.56^{* *}$

( 2.41$)$

33.90

( 1.32 )

.97

** Coefficlent is significantly different from zero at the. 05 level
* Coefficlent is significantly different trom zero at the . 10 level 
Using these results we estimate the Medicaid expenditure elasticity and its components. Table 4 reports these elasticities for separately for proprietary and "not for profit" homes. The elasticities are calculated at the maan of the proprietary and "not for profit" samples, respectively. The total elasticities are reported in the last column of table 1. The proprietary elasticity is .117 , and is substantially higher than the "not for profit" elasticity which is .061 .

The other columns of table 4 report components of the elasticities. The first column reports the price effect, which is .146 for proprietary homes and and .078 for "not for profit" homes. The larger proprietary price effect reflects the fact the Medicaid "plus" factors are nigher for proprietary homes, and "not for profit" homes have higher average costs. The second column reports the quality effect which is the cost elasticity times the ratio of average cost to the Medicaid reimbursement rate. As with the price effect, the proprietary quality effect is twice as large as the "not for profit" effect. specifically, it is -.063 for proprietary homes is -.063 and -.027 for "not for profit" homes. The larger proprietary effect is a result of a much bigger cost elasticity. Specifically, the cost elasticity is -.73 for proprietary homes and is -.029 for "not for profit homes. The third column reports the quantity effect, and again the proprietary effect is substantially higher than the "not for profit" effect. Specificaly, the proprietary quantity effect is .034 and the "not for profit effect is .01 .

TABLE 4

MEDICAID EXPENDITURE ELASTICITIES

\begin{tabular}{lcccc} 
& $(r / R)$ & $N_{c}(A C / R)$ & $N_{\text {m }}$ & $N_{6}$ \\
\hline PROPRIETARY HOMES & .146 & -.063 & .034 & .117 \\
-NOT FOR PROFIT* HOMES & .078 & -.027 & .010 & .061
\end{tabular}


13

In order to guage the magnitude of these effects, we translate them into dollar figures. In 1983, total Medicaid expenditures were $\$ 14$ billion, of which approximately $\$ 9.94$ billion was reimbursed to proprietary institutions, $\$ 2.52$ billion to "not for profit" institutions, and the rest to government operated institutions. Consider a one percent increase in the Medicaid "plus" factor. At the respective means, this amounts to a $\$ .68$ rise in $r$ per Medicaid patient day for proprietary institutions, and a $\$ .41$ rise for "not for profit" institutions.

The annualized expenditure effects of such a one percent rise in $r$ are reported in table 5. The proprietary price effect is an increase of $\$ 1,451$ million in Medicaid expenditures, while the "not for profit" price effect is $\$ 197$ million increase, implying a total price effect of $\$ 1,648$ million. Next, the proprietary quality effect is a $\$ 626$ million decrease in Medicaid expenditures, while the "not for profit" quality effect is a $\$ 68 \mathrm{million}$ decrease, implying a total quality effect of $-\$ 954$ mfllion. The proprietary quantity effect is a $\$ 338 \mathrm{million}$ increase in Medicald expenditures, while the "not for prcfit" quantity effect is a $\$ 25 \mathrm{million}$ increase, implying a total quantity effect of $\$ 363$ million. Finally, the total proprietary effect is an increase of $\$ 1,163$ million in Medicaid expenditures, while the total "not for profit" effect is an increase of $\$ 154$ million, implying a $\$ 1,317$ mfllion total increase.

TABLE 5

THE EFFECTS (in millions of dollars) OF A 12 IMCREASE

IN THE MEDICAID "PLUS" FACTOR ON MEDICAID EXPENDITURES

\begin{tabular}{lrrrr} 
& $(r / R)$ & $N_{c}(A C / R)$ & $N_{h}$ & \multicolumn{1}{c}{$N_{e}$} \\
\hline PROPRIETARY HOMES & 1,451 & -626 & 338 & 1,163 \\
- MOT FOR PROFIT" HOMES & 197 & -68 & 25 & 154 \\
TOTAL & 1,648 & -694 & 363 & 1,317
\end{tabular}




\section{CONCLUSIONS}

This paper estimates the elasticity of Medicaid expenditures on nursing home care with respect to a change in the Medicaid "plus" factor, and decomposes that elasticity into price, quality, and quantity effects. The elasticities are estimated for both proprietary and "not for profit" nursing homes, with the proprietary elasticity being approximately twice as large as the "not for profit elasticity. Specifically, the proprietary elasticity is .117, while the "not for profit" elasticity is .061 .

The results show that small increases in the Medicaid "plus" factor can lead to large rises in expenditures. We estimate that a one percent across the board increase in the Medicaid "plus" factor ( $\$ .68$ per patient day for proprietary homes, and $\$ .42$ per patient day for "not for profit" homes) leads to approximately $\$ 1,317 \mathrm{million}$ increase in annual Medicaid expenditures.

In the decomposition, as expecteo, the price and quantity effects are positive, and the quality effects are negative. In fact, the quality effect is quite substantial, and ignoring it would lead to an extremely large over estimate of the Medicaid expenditure elasticity. The quality effect is -.064 for proprietary homes and -.027 for "not for profit" homes. In dollar terms, the quality effect of a one percent rise in the Medicaid "plus" factor amounts to a decrease of approximately $\$ 694 \mathrm{million}$ in Medicaid expenditures. Hence, If the quality effect were ignored, the expenditure elasticity would be over stated by approximately fifty three percent. 


\section{FOOTNOTES}

1 The source of all data on national nursing home expenditures is Gibson, Waldo, Levit, and Lazenby (1984).

2 In 1982, 37 states used some form of cost plus reimbursement, 6 states used a flat rate, and the remaining 7 used a combination of the two. See Harrington and Swan (1984).

3 The CON cost containment program was passed into law in response to the rapid growth of the health care industry during the late 1960 's and early 1970's. It requires that, in order to expand an existing nursing home or bullo a new one, the government must certify that the proposed factlity is indeed "needed". Effectively, CON limits the existing capacity of existing nursing homes and new entry into the market. It was thought that the expansion could be contained by limiting the avallable supply of nursing home beds.

4 The excess Medicaid demand hypothesis is supported empiricaliy in scanlon (1980). Further, there is casual evidence in support of binding con capacity and entry constraints. First, most nursing homes operate above $90 \%$ capacity. second, there is a long list of individuals in hospitals waiting for nursing home openings. Finally, states such New York have imposed moratoriums on nursing home expansion.

5 These results are presented in a formal analytic context in Gertler (1985a) and supported empirically in Gertler (1985b).

6 This representation of a firm's output is similar to general models analyzed in spence (1975), Sheshinski (1976), and Leffler (1982), and to nursing home models analyzed in Bishop (1980) and Palmer and Vogel (1983).

7 Analytically, the sign of the comparative statics in this model is not completely unambiguous. These results are generated in a slightly more restrictive model in Gertler (1985a) and supported empirically in Gerlter $(1985 b)$.

8 For example see Hansmann (1981), Newhouse (1970), and Pauly and Redisch (1973)

9 There are several alternatives to modeling "not for profit" nursing homes in this fashion. Some "not for profit" homes could be profit maximizers who have obtained "not for profit" legal status in order to take advantage of the tax breaks. In this case, profits are taken in the form of salary and rent. other non-altruist "not for profit" homes, could be operated by non-owner managers who are personal utillty maximizers. These managers may manipulate the operation of the home so as to maximize their own income, prestige, and security. The result is an inefficient employment of resources. Hence, these homes are not cost minimizers. This case is discussed in Frech and Ginsburg $(1980)$. The altruism assumption suggests cost minimization.

10 Footnote 7 applies here as well.

11 Formaliy $\tilde{n}_{e}=(\partial E / \partial r)(r / E), \tilde{n}_{c}=(\partial C / \partial r)(r / C)$, and $\tilde{n}_{m}=(\partial M / \partial r)(r / M)$. 
12 The linear approximation was chosen over a logarithmic approximation for several reasons. First, as pointed out by White (1980), a linear approximation is just as good as a logarithmic approximation. Second, the data includes several variabies that are measured as proportions. The proportions already are normalized to a base, and therefore, the logarithmic function normalizes already normalized variables. Further, a number of observations have zero values for some variables which causes problems in the logarithmic case.

13 Footnote 12 applies as well. An additional issue is why we use a first order approximation instead of a second order approximation of the cost function. A second order approximation, such as the translog, would require estimating a model with over ninety parameters. It is not clear how much better a second order approximation is in the case of such a large model. Therefore, in the name of parsimony, a first order approximation was used.

14 The supplies price index is total supplies expenditures divided by a supplies quantity index. The supplies quantity index is calculated as the total expenditures on supplies divided by an index of the price of supplies. The supplies price index is a weighted average of the prices of the commodities that constitute nursing home supplies. These commodities are drugs, other medical supplies, food, energy, and other supplies. The prices of these commodities are national price indices in 1977 dollars, and are reported in the Department of Health and Human Services report, HEALTH CARE FINANCING TRENDS, 1980. The weights are the proportion of a nome's total supplies expenditures accounted for by the particular commodity.

15 The health status index is computed from disablitity scores assigned patients. The disabilty level of each patient in eight functional areas is reported in the survey. The disabilty level in each functional area takes on one of three values: self care, partial care, and total care. The functional areas are walking, transferring, wheeling, eating, tolleting, bathing, dressing, and breathing. Waiking, transferring, and wheeling were treated as mutually exclusive categories. Each nome reports the number of patients in each cell, where a cell is defined by functional area and disability level. The cells are then aggregated by disability level. After that, the self care aggregate is multiplied by zero, the partial help aggregate by seven, and the total help aggregate by fourteen. The scores are then summed and divided by the total number of patients times 100. The result is an index of the average ill-health of the patients in a facility. This index is used for the purposes of quality control (see Uilimann (1983)).

16 For each home, the market population is computed as a weighted sum of the number of persons over age 65 in each county, using the home's proportions of private patients from the counties as weights. Similarly, the per capita income of the population in a home's market area is computed as the weighted sum of the counties' per capita incomes, using the same welghts.

17 since each county is treated as a separate market, and each home participates in several county markets, the concentration of a home's private pay patient market depends upon its degree of participation in the various county markets. Therefore, the concentration level of a home's private pay patient market is a weighted sum of the county market concentration levels, using the home's proportion of private pay patients from each county as weights. The concentration of a county private pay patient market is computed using a Herfindahl index, which is based on each home's share (proportion) of a county's private pay patients. Specifically, it is the sum of squared shares (see Scherer (1980) pp. 58). Entry reduces the value of this index. 


\section{REFERENCES}

Bishop, C. E. (2980), "Nursing Home Cost Studies and Reimbursement Issues," Health Care Financing Review, Vol. 2, PP. 47-64.

Frech, H. E., and P. B. Ginsburg (1980), "The Cost of Nursing Home Care in the Urited States: Government Financing, Ownership, and Efficiency," in Health, Economics, and Health Economics, edited by $J$. Van der Gaag and M. Periman, North Holland, Amsterdam, Pp. 67-81.

Gertler, P. J. (1985a), "Regulated Price Discrimination and Ouality: The Implications of Medicaid Reimbursement Policy for the Nursing Home Industry," Working Paper No. 267, Department of Economics, State University of New York at Stony Brook.

Gertler, P. J. (1985b), "Subsidies, Quaity, and Regulation in the Nursing Home Industry," Working Paper No. 268, Department of Economics, State University of New York at Stony Brook.

Gibsnn, R. M., D. R. Waldo, K. R. Levit, and H. Lazenby, (1984) "National Health Care Expenditures," Health Care Financing Review, Vol. 6, No. 1, pp. 1 - 38 .

Hansmann, H. (1981), "Non-Profit Enterprises in the Performing Arts," Bell Journal of Economics, Vol. 12, pp. 341-361.

Harrington, C. and J. Swan (1984), "Medicaid Nursing Home Reimbursement Policies, Rates, and Expenditures," Health Care Financing Review, Vol 6. No.1, PP. $39-49$.

Leffler, K. D. (1982), "Ambiguous Changes in Product Quality," American Economic Review, Vol. 72, pp. 956-967.

Newhouse, J. P. (1970), "Towards a Theory of Non-Profit Institutions: An Economic Model of a Hospital, "American Economic Review,

Vol. 60, pp. 64-75.

New York State Department of Health, Office of Health Systems Management (1980), "Title XIX Nursing Home Cost Survey."

Palmer, H. C. and R. J. Vogel (1983), "Models of the Nursing Home" in LongTerm Care: Perspectives From Research and Demonstrations, edited by R. J. Vogel and H. C. Palmer, Health Care Financing Administration, U.S. Department of Health and Human Services.

Pauly, M., and M. Redisch (1973), "The Not for Profit Hospital as a Physicans" Cooperative," American Economic Review, Vol. 63, pp. 87-100.

Scanion, W. J. (1980), "The Market for Nursing Home Care: A Case of an Equilibrium with Excess Demand as a Result of Public Policy," unpublished Pri.d dissertation, Department of Economics, University of Wisconsin at Madison. 
Scherer, F. M. (1980), Industrial Market Structure and Economic Performance, Rand-McNally.

Sheshinski, E. (1976), "Price, Quality, and Quantity Regulation in Moropoly Situations," Economica, Vol. 43, pp. 417-429.

Spence, M. (1975), "Monopoly, Quality, and Regulation," Bell Journal of Economics, Vol. 6, pp. 417-429.

Ulimann, S. G. (1983), "Cost Analysis and Facility Reimbursement in the LongTerm Health Care Industry," Department of Economics Working Paper, University of Miami.

Waldo, D. R. (1981), Health Care Financing Trends, Health Care Financing Agency, Depertment of Health and Human Services, U.S. Government Printing office, Washington D.C.

White H. (1980), "Using Least Squares to Approximate Unkown Regression Functions," International Economic Review, vol. 21, No. 1, pp. 149-170. 